\title{
Climate change and the Antarctic marine ecosystem: an essay on management implications
}

\author{
P.N. TRATHAN ${ }^{1}$ and D. AGNEW ${ }^{2}$ \\ ${ }^{I}$ British Antarctic Survey, NERC, High Cross, Madingley Road, Cambridge CB3 OET, UK \\ ${ }^{2}$ Marine Resource Assessment Group Ltd, 18 Queen Street, London W1J 5PN, UK \\ pnt@bas.ac.uk
}

\begin{abstract}
In this paper we review evidence for, and anticipated consequences of, climate change in Antarctic marine communities, examining the potential impacts on invertebrates and vertebrates alike and exploring plausible outcomes for species, with examples principally from the Antarctic literature. We suggest that industries with the greatest potential to aggravate climate change impacts on marine communities are marine capture fisheries. In the Southern Ocean, harvesting is governed under the Convention for the Conservation of Antarctic Marine Living Resources (CCAMLR). CCAMLR espouses an ecological management framework and so has the capacity to mitigate harvesting impacts such that they do not worsen impacts from climate change. We discuss some of the implications of climate change and advocate that CCAMLR address certain key issues if it is to fulfil its international obligations. It will be essential for CCAMLR to determine relative risks (uncertainties), impacts and timescales, of various processes consequent on climate change. Such risk assessments should be feasible with current knowledge and should provide a focus for future work. We believe it will be important to prioritize issues that reduce impacts and uncertainties by the greatest degree, and propose that future plans should involve shared responsibility (e.g. with SCAR etc.) for each of the risks described.
\end{abstract}

Received 25 July 2009, accepted 2 March 2010

Key words: CCAMLR, fishing, harvesting, monitoring, Southern Ocean, variability and change

\section{Introduction}

At present, direct human activities in the Southern Ocean principally include fishing, science and tourism, each of which is subject to varying degrees of supervision and management (Clarke \& Harris 2003). Compared to many other parts of the World Ocean, the consequential impacts of these activities on ecosystem processes are relatively minor (Halpern et al. 2008), though they have been much greater in the past (Bonner 1980, 1984, Kock 1992). In contrast, indirect human impacts, particularly those arising as a consequence of greenhouse gas emissions originating from beyond the Southern Ocean, are likely to be very much more considerable and very much more likely to impact upon ecosystem processes and structure. Thus, Clarke \& Harris (2003) ranked climate change as one of the most important threats to the future of Antarctic marine ecosystems, second only to that of Illegal, Unregulated or Unreported (IUU) fishing.

The Antarctic is a major component of the Earth's climate system, linked through global atmospheric and oceanic circulations (Solomon et al. 2007). Such links mean that the consequences of global greenhouse gas emissions are likely to be evident at a variety of scales, both temporally and spatially (Parry et al. 2007). Furthermore, in the Antarctic, changes in stratospheric ozone are now also thought to have contributed to observed climate change effects (Thompson \& Solomon
2002), with the interaction effects of ozone and $\mathrm{CO}_{2}$ increasingly recognized as important (Mayewski et al. 2009).

All marine ecosystems in the Antarctic may be influenced by climate change. For example, the progressive warming in the Southern Ocean (Gille 2002) has been associated with a decline in Antarctic krill (Euphausia superba Dana) (Atkinson et al. 2004) and an associated decline in the population size of various seabirds and seals (Weimerskirch et al. 2003). Other observations also suggest that alterations to habitat via changes in sea ice characteristics caused by regional climate warming have had a detrimental impact on the prey of seabird and seal populations (Trathan \& Murphy 2002, Trathan et al. 2003, 2006, 2007, Forcada et al. 2005, 2006, Murphy et al. 2007). Indeed, it is perhaps not surprising that marine systems close to the Antarctic Peninsula, the South Orkney Islands and across the Scotia Sea have been amongst the first affected given the recent, regional, rapid rise in temperatures close to the Peninsula (Vaughan et al. 2003). The most significant warming trends across the Peninsula occur for the western and northern parts. Here Faraday/ Vernadsky Station has experienced the greatest statistically significant $(<5 \%$ level $)$ trend with temperature increases over the period $1951-2001$ of $+5.6 \pm 4.3^{\circ} \mathrm{C}$ per century (Vaughan et al. 2001). Rothera Station, $300 \mathrm{~km}$ to the south of Faraday, has experienced an even greater warming trend for the period 1978-2001 with increases of $+11.0 \pm 13.0^{\circ} \mathrm{C}$ per century (Vaughan et al. 2001), but the duration of the data record 
and the large interannual variability in the recorded temperatures means that this trend is not statistically significant.

The region of warming extends from the southern part of the western Antarctic Peninsula north to the South Orkney Islands. The rate of warming decreases away from Faraday/Vernadsky Station with the long record from Signy Island, South Orkney Islands, showing only a warming of $+0.25^{\circ} \mathrm{C}$ per decade (Quayle et al. 2002), and a different annual pattern (Signy has warmed mostly in the summer, while Faraday/Vernadsky has warmed more in the winter). Further north at the more northerly sub-Antarctic islands, changes are also apparent, particularly in ocean temperature (Whitehouse et al. 2008) and glacier retreat (Cook et al. 2010) though clear terrestrial trends are not yet well described (Convey 2006, 2007).

Elsewhere in the Antarctic, beyond the Antarctic Peninsula and the Scotia Sea, warming and the loss of sea ice are less pronounced, and there may even be a slight cooling across much of the continent (Vaughan et al. 2003, Turner et al. 2009b). Nevertheless, some recent studies suggest that warming may be more extensive than previously thought (Steig et al. 2009).

Global and even regional climate change will bring with it a number of potential risk factors for the World Ocean, including: increasing sea temperatures, increasing sea height, changes to global ocean thermohaline circulation, increasing ocean acidification, and changes to the freshwater content following glacial melt (Parry et al. 2007, Nellemann et al. 2008). For the Polar Regions where changes in sea ice patterns are also likely to occur, other consequential impacts will potentially include increasing accessibility for fishing, science and tourism, changes to commercial transport and shipping movements, increased pollution, and the introduction of alien species - all of which carry significant risks to marine ecosystems. Indeed, some of these risks (such as the introduction of alien species in combination with altered ecosystem properties) remain poorly understood for marine ecosystems, despite the fact that similar risks have been examined over a number of years and are now considered to be key issues for terrestrial Antarctic systems (cf. Frenot et al. 2005).

The consequences of climate change are potentially profound. In this review we examine some of the potential outcomes of climate change and suggest possible approaches for effective management of the Antarctic marine ecosystem. First we look at some of the taxa-specific threats, in order to understand the range of possible outcomes for a variety of species within the food web, and then consider some of the management related issues and how these might be addressed if future management decisions are to be successful. Ultimately, as the drivers of climate change originate outside the Antarctic, options within the Antarctic to restrict impacts are limited. Nevertheless, exacerbation of climate change impacts should not be allowed to occur through inappropriate management practices. Thus, as climate change potentially introduces a greater level of ecosystem uncertainty, successful ecosystem outcomes potentially mean that management practices may need to be more conservative.

A recent synthesis of Antarctic climate change (Turner et al. 2009a) summarizes some of the most important physical effects and produces limits on the anticipated temperature increase. This summary highlights i) how the ozone hole has delayed the impact of greenhouse gas increases on the climate of the continent (Turner et al. 2009b), ii) how the Antarctic Circumpolar Current has warmed faster than the global ocean as a whole (Gille 2002), iii) how regional warming caused by intensification of the westerly winds (due to the ozone hole) is melting ice shelves along the eastern Antarctic Peninsula (Turner et al. 2009b), how since 1980 there has been a $10 \%$ increase in Antarctic sea ice extent, particularly in the Ross Sea region, as a result of the stronger winds around the continent (due to the ozone hole), while regional sea ice has decreased west of the Antarctic Peninsula due to changes in local atmospheric circulation and this has also been linked with the very rapid warming seen over land on the west coast of the Peninsula (Turner et al. 2009b), and how over this century the ozone hole is expected to heal, allowing the full effects of greenhouse gas increases to be felt across the Antarctic, with a predicted warming of about $3^{\circ} \mathrm{C}$ across the continent (Turner et al. 2009b).

\section{Potential impacts on invertebrates}

Antarctic marine invertebrates are typically considered to be stenothermal, that is only capable of living or growing within a limited range of temperatures (e.g. Peck \& Conway 2000). If this proves to be the case, then they should be highly sensitive to predicted climate change. Experiments have shown that most species, including a wide range of (adult) invertebrates, have upper lethal temperatures below or near to $10^{\circ} \mathrm{C}$ (Peck et al. 2004). Some can survive just a $7^{\circ} \mathrm{C}$ temperature window (Peck 2005, Peck et al. 2006, Pörtner et al. 2007). However, even in the most severe warming scenarios a temperature rise of this magnitude in the Southern Ocean is unlikely by 2100 . Nevertheless, organisms can be critically affected (e.g. chronic effects on feeding and reproduction) at lower temperatures long before lethal levels arise (Peck et al. 2006). Key life-history stages might be particularly sensitive to temperature. Nonetheless, whether populations or species can survive future temperature rises may actually be dictated by the sensitivity of all their life history stages to chronic as well as to lethal effects.

Ocean acidification associated with increased $\mathrm{CO}_{2}$ levels is also predicted to have a significant impact on calcium carbonate skeletal maintenance of invertebrates (Royal Society 2005). Aragonite based corals are most at risk, but octocorals that use primarily calcite for their skeletons may also be vulnerable. Whether species are positively or negatively impacted by increased temperatures, $\mathrm{CO}_{2}$ 
levels or acidity levels, entire planktonic assemblages or communities may change and consequently potentially affect entire food web systems. However, it is still unclear how the rich invertebrate biodiversity of the Southern Ocean will respond to medium/long-term warming. Changes have been found in some pelagic and benthic populations of some species over the past few decades, but as yet none have been definitively linked to climate change. Most of the evidence currently being discussed for how invertebrate organisms might cope with temperature rises (or $\mathrm{pH}$ changes) is experimental (Peck et al. 2006, Pörtner et al. 2007). However, it is clear that experimental approaches cannot yet reveal all of the evolutionary processes involved (Peck et al. 2009). For example, there are a number of species of marine invertebrates that exist both at the Antarctic Peninsula and at the sub-Antarctic island of South Georgia; at this latter more northerly site, the prevailing temperature regime is above the experimental limits determined for some of the species used from the Peninsula. Indeed, a species' ability to acclimate is critical and rates of warming are crucial (Peck et al. 2009).

Most of the impacts of climate change on invertebrate species are likely to affect benthic communities though some impacts are also likely to affect pelagic communities. The chronic impacts on invertebrates currently considered to be important are (Turner et al. 2009a, Royal Society 2005):

a) Loss of habitat. The effects of direct warming might lead to reduced seasonal sea ice habitat, critical for some species. This is likely to be a significant factor for those euphausiid species that currently utilize sea ice in their juvenile phases, such as krill (Nicol 2006, Stammerjohn et al. 2008).

b) Changes in medium-term and long-term physical disturbance. This will be mainly due to: increases in coastal sedimentation associated with ice melt; increases in ice-loading and coastal concentrations of large icebergs from collapsing ice-shelves, and freshening of surface waters leading to other changes such as altered stratification (Smale \& Barnes 2008).

c) Physiological effects. The effects of direct warming might lead to reduced performance in critical activities and thus geographic and bathymetric migrations. Increased metabolism with temperature may impact on growth or feeding requirements (Peck et al. 2006). Major stresses will also include ocean acidification and freshening of the ocean, both of which will probably impact upon the physiology of species (Royal Society 2005). Many effects, however, are still essentially unknown.

d) Increased ocean acidification. Increased $\mathrm{CO}_{2}$ levels will result in increased ocean acidification, leading to skeletal synthesis and maintenance problems, particularly for deep water corals in the Antarctic, but also for other invertebrates with aragonite skeletons such as pteropod molluscs (Royal Society 2005). Carbonate de-saturation is predicted to occur first in deep high latitude waters, and therefore may significantly affect coral-based vulnerable marine ecosystems on Antarctic shelf slopes within the next 100 years (Royal Society 2005).

e) Deoxygenation of the oceans. Warmer water holds less gas and therefore less $\mathrm{O}_{2}$, which may lead to a slight deoxygenation of surface waters (Aoki et al. 2005). However, the disruption of currents and down-welling could ultimately lead to more serious deoxygenation of deeper layers. Such effects are difficult to predict however, as increased wind stress (Chan \& Liu 2004, Hogg et al. 2008) would lead to increased overturning.

f) Competition with invasive species. Competition may arise following natural range extensions of cold temperate species, or following human-induced range changes. However, compared with the terrestrial domain (Frenot et al. 2005, Chown \& Convey 2007), such competitive interactions in the Antarctic marine environment are not well understood. Throughout much of the Antarctic, the Polar Frontal Zone acts as a barrier to larval and juvenile distribution. However, the barrier is not full depth and not always effective (Barnes et al. 2006); for example, in the South Atlantic sector of the Southern Ocean a number of benthic organisms already occur both on the Patagonian Shelf and around the sub-Antarctic and Antarctic islands. Thus, the likelihood of invasion following ocean warming is high (Aronson et al. 2007). The narrow physiological tolerance ranges of many Antarctic organisms may also make them poor competitors in an altered environment, compared with immigrants from more northerly areas (Peck et al. 2006).

\section{Potential impacts on higher trophic levels}

The impacts of climate change may cascade to higher trophic levels (Castini et al. 2008). Such cascades may occur through multiple pathways along which climatic and anthropogenic pressures can propagate through food webs; these pressures may act synergistically to cause and stabilize regime changes and are often mediated through zooplankton, which have a crucial role in Antarctic ecosystem processes (Mollmann et al. 2008). Consequently, species of direct interest to fisheries managers and tourist operators may be affected. For fish, seabirds and marine mammals impacts may be manifest in a variety of ways, with most responses evident as changes in behaviour, phenotypic expression or in genotype that result in one or more of the following (Chambers et al. 2005, Trathan et al. 2007):

a) Changes in distribution. It has been suggested that warming will make the sub-Antarctic (and Antarctic) more habitable to some more northerly ranging groups that are currently poorly represented, for instance sharks (www.sciencecentric.com/news/080216313.htm 2008), 
and southern blue whiting (Micromesistius australis Norman) which is suspected of having undertaken feeding migrations from the Patagonian shelf to the South Shetland and South Orkneys (Shust 1978, Agnew et al. 2003). Thus, at its simplest, changes in distribution may be evident as a pole-ward shift in range. However, given the complexity of landforms and ocean circulation in some regions, changes in distribution may be more complex, limited by both circulation and primary productivity. Landmasses (and continental shelves) in the Southern Ocean are essentially a set of island systems, such that the smooth latitudinal shifts currently seen and expected in oceans bordering continents that run north-south (for instance in the North Sea; Perry et al. (2005); and modelled by Cheung et al. (2009)) cannot simply be translated to the Southern Ocean. Hence, it is not safe to assume that there is a simple relationship between latitude and environmental conditions, and it is the latter rather than the former that limits ecological ranges. In the high latitudes adjacent to the continent, pole-ward shifts are not feasible for some species; for example, emperor penguins (Jenouvrier et al. 2009) cannot move further south, given their dependence on both fast sea ice and access to foraging grounds. In contrast at lower latitudes, chinstrap penguins (Pygoscelis antarctica Forster), which breed mainly on the Antarctic Peninsula and islands of the Scotia Arc, have increased in numbers over the latter part of the 20th century (Laws 1985, Rootes 1988). At the same time, they have expanded their range southward along the western side of the Antarctic Peninsula (Parmelee \& Parmelee 1987, Poncet \& Poncet 1987) into areas historically dominated by the closely related Adélie penguin ( $P$. adeliae Hombron \& Jacquinot). Fraser et al. (1992) suggested that the reason that chinstrap populations were able to expand their range was that a long-term decrease in the frequency of cold years with extensive sea ice cover induced by environmental warming changed the relative availability of critical chinstrap and Adélie wintering habitats. Subsequently, Trathan et al. (1996) identified that it was the sea ice conditions outside the breeding season that played an important role in penguin population processes.

b) Match-mismatch changes. Matching the timing of reproductive effort to prey availability is critical for successful breeding in many higher trophic level taxa. Many areas outside the Antarctic are already experiencing the impacts of such effects. For instance, changes in the availability of key copepod species at the time of cod egg hatching times appears to have been the most significant environmental factor impacting the reduction of cod recruitment in the North Sea in the early 1990s (Beaugrand et al. 2003,
Brander 2005). Match-mismatch also potentially explains highly variable recruitment in some fish species, such as Patagonian toothfish (Dissostichus eleginoides Smitt) that rely as juveniles on key prey species (Collins et al. 2007), and which appear to experience only episodic recruitment (Belchier \& Collins 2008). Match-mismatch also explains highly variable recruitment for some penguin colonies on the Antarctic Peninsula (Fraser \& Hoffmann 2003) and at South Georgia, where penguin breeding performance is reduced when inputs of krill appear late in the season (BAS unpublished data). These match-mismatch events are likely to increase as warming oceans and changing oceanographic structures alter the distribution of pelagic ecosystems with respect to islandbased ecosystems. Indeed, Gille (2008) has recently highlighted the poleward migration of the Antarctic Circumpolar Current, possibly driven by long-term poleward shifts in the winds of the region, as represented by the Southern Annular Mode. This will potentially have profound consequences for many island ecosystems.

c) Changed patterns of movement. If the distribution of important prey species is altered by changes in the climate, then regular predator commuting between breeding sites and foraging grounds may be affected. Similarly, migration routes between summer and winter foraging grounds may also be altered. For example, Fraser \& Hofmann (2003) suggested that there is a direct, causal relationship between climate driven variability in sea ice cover, krill recruitment, prey availability and predator foraging ecology. Fraser \& Hofmann (2003) reported that in the West Antarctic Peninsula region, krill abundance tends to decrease following years of poor krill recruitment (after years of anomalously low sea ice extent), and to increase following years of good krill recruitment (after years of anomalously high sea ice extent); they go on to suggest that penguin foraging trip duration is then affected when krill abundance falls below a critical threshold density. Above the density threshold of krill, penguin foraging trip duration remains more or less constant, while below it, foraging trip duration increases with decreasing krill abundance. However, Fraser \& Hofmann (2003) noted that changes in krill abundance alone are probably not the only factors affecting foraging interactions.

d) Changes in population density. Population sizes and densities may change due to the direct effects of extreme environments, through impacts on vital rates, such as survival, fertility, or breeding success (Forcada et al. 2008). Populations may then fragment, and genetic diversity may be reduced. Recently, Forcada et al. (2008) examined the consequences of warming for a 
variety of Antarctic upper trophic level taxa and looked at their ability to survive changing patterns of climate and environmental variation. Forcada et al. (2008) found strong statistical support for selection of life history traits that reduced interannual variation in fitness, including for species as diverse as emperor penguins, snow petrels, southern fulmars, Antarctic fur seals and Weddell seals. These authors suggested that all of these species maximized their fitness by maintaining low interannual variance in the survival of adults and in their propensity to breed annually, properties that strongly influence population growth rates. All of the species were able to buffer their vital rates against the effects of recent climate-driven habitat changes, apart from Antarctic fur seals breeding in the southwest Atlantic. In this area of the Atlantic, the rapid increases in ecosystem fluctuation, associated with increasing climate variability, has affected fur seal food supplies, principally Antarctic krill; krill are now more limited and less predictable than in previous decades (Atkinson et al. 2004). This has increased the costs of breeding for female fur seals, causing significant short-term changes in population structure through mortality and low breeding output. Forcada et al. (2008) suggest that changes occur now with a higher frequency than the mean female fur seal generation time, and consequently limit their adaptive response. Also that fur seals are more likely to rely on phenotypic plasticity to cope with short-term changes in order to maximize individual fitness. Forcada et al. (2008) conclude that species with less flexible life histories that are more constrained by fluctuation in their critical habitats, such as sea ice, may experience demographic changes, population compensation and changes in distribution. Such changes have already been observed for penguin species living in the Antarctic Peninsula and adjacent sub-Antarctic islands. More recently, Jenouvrier et al. (2009) have also suggested that emperor penguin colonies may also suffer similar population declines due to climate change.

e) Changes in phenology. As a consequence of changed environmental conditions, a wide variety of processes could alter in their absolute timing over the course of a year, including, for example, dates of arrival at a spawning/breeding site, dates of spawning in fish, dates of egg laying and of fledging in birds, or dates of pupping and weaning in marine mammals (e.g. Barbraud \& Weimerskirch 2006a, 2006b). If temperature is a direct cue and if the degree of regional warming varies between regions, then some processes may also change in their relative timing and in their relationship to each other and this could then have further ecological implications. The timing of egg laying for gentoo penguins breeding at Bird Island, South Georgia has changed in recent years.
The appearance of the first egg at two monitored study colonies is now some ten days earlier, on average, than it was 18 years ago; also, the date by which $75 \%$ of eggs have been laid, is also similarly much earlier (BAS unpublished data). In contrast, Barbraud \& Weimerskirch (2006a, 2006b) have shown that the date of first arrival and the date of first egg laying have advanced significantly for a range of Antarctic seabirds breeding in East Antarctica, where the sea ice season duration has increased in recent years.

f) Changes in behaviour. Diurnal patterns of activity and behaviour may also change as a consequence of altered environmental conditions. For example, net foraging effort may increase for gentoo penguins if environmental cascades result in altered ecosystem properties and differences in preferred prey abundance (BAS unpublished data). Similarly, other behaviours may also alter as a result of changed environmental conditions. For instance, in warm years that are also years of low krill availability, macaroni penguins may switch prey from Antarctic krill to Themisto gaudichaudii Guerin (BAS unpublished data). Equally, shivering responses by young seabirds may also increase if they are exposed to elevated levels of rain, rather than snow (Hooper 2007).

g) Change in community interactions. If climate change impacts upon a number of trophic levels, then wholesale community changes may become evident. This may be apparent as a 'regime shift' (Rodionov 2004) or as changes in the foodweb as new species interactions or predator-prey interactions develop. Climate variability is known to have important effects on marine ecosystems (Trathan \& Murphy 2002, Trathan et al. 2003, 2006, 2007, Forcada et al. 2005, 2006, 2008, Leaper et al. 2006, Murphy et al. 2007), with repercussions that range in scale from those that impact upon individuals to those that impact the entire food web. Climate-induced changes in the abundance of species in lower trophic levels can cascade upwards to apex predators by depressing their vital rates (Murphy et al. 2007, Forcada et al. 2008). For example, climate warming and associated sea ice reductions in the Antarctic have modified habitat conditions for some penguin species (Forcada et al. 2006). These include Adélie, chinstrap and gentoo penguins, which now demonstrate remarkable population responses to regional warming. However, understanding the causal processes is complex, given the inconsistencies in the direction of population changes between species at different study sites. The numbers of gentoo penguins breeding on the South Orkney Islands have increased significantly over the past three decades, whereas the numbers of chinstrap and Adélie penguins have both declined. These trends 
have occurred in parallel with regional long-term warming and significant reduction in sea ice extent. Periodical warm events have led to cycles in sea ice leading to reductions in prey biomass, and simultaneous interannual population changes in the three penguin species. Adélie penguins have been poorly buffered against reductions in sea ice; their population response has been negative and linear. Conversely, though gentoo penguins have also been negatively affected in years with extensive sea ice, their populations have increased, potentially due to increases in their available niche. Finally, though chinstrap penguins have also been negatively affected in years of increased sea ice cover, their responses have been variable and nonlinear. Thus, the consequences of global climate perturbations have affected the regional marine ecosystem, with repercussions for penguin food supply and competition for resources. Ultimately, variability in penguin populations reflects the local balance between penguin adaptation to ice conditions and trophic-mediated changes cascading from global climate forcing.

h) Changes in morphology or physiology. As environmental conditions alter, animal populations may respond by changes in morphology, such as changes in body mass or breeding performance, either as a result of energetic constraints, or because of altered physiological efficiencies. Indeed, the overall conclusion of Cheung et al. (2009), was that the physiological specialization of high latitude marine organisms will make them particularly vulnerable to extinction, and that the maximum potential for species turnover and invasions will be in the $40^{\circ}-60^{\circ} \mathrm{S}$ region, if oceanography permits this. Changes in morphology and physiology potentially lead to sub-speciation and eventually effective speciation. For example, using Bayesian inference of ancestral areas Baker et al. (2006) showed that an Antarctic origin is highly likely for extant taxa of penguins, but that more derived taxa occur in lower latitudes. Baker et al. (2006) further suggest that, as Antarctica cooled in the Eocene (40 m.y.a.), modern penguins expanded via the circumpolar current to the oceanic islands within the Antarctic Polar Frontal Zone, and later to the southern continents. Thus, global cooling has had a major impact on penguin evolution. Penguins only reached cooler tropical waters in the Galapagos Islands about 4 m.y.a., and have not yet crossed the equatorial thermal barrier. Though some penguin species have evolved into subspecies (Williams 1995), no subspecies differences have been attributed to recent environmental change.

Many of the biological impacts described above may be plausibly attributed to climate change; however, evidence of unambiguous, causal mechanisms, remains elusive and rigorous and comprehensive examination of the underlying processes is still required (Croxall et al. 2002), particularly for those species that spend much of their lives outside the Southern Ocean in neighbouring ecosystems.

\section{Ecosystem considerations}

The Southern Ocean is a site of rapid regional climate change (Parkinson 2002, 2004, Vaughan et al. 2003). However, predictions concerning the possible impacts of climate change are subject to a high degree of uncertainty, with differing but plausible outcomes. In addition to such uncertainty, there is uncertainty about the pre-exploited state, whether it was stable, oscillating stable or whether there were apparent trends. Today it is a highly dynamic system with considerable interannual variability superimposed upon apparent trends in both physical and biological components. Such dynamic systems are by their very nature difficult to predict with any degree of certainty (e.g. Trathan et al. 2006, Murphy et al. 2007). Consequently, understanding ecosystem change in the Southern Ocean is complex, requiring information over many spatial and temporal scales.

Elsewhere in the World Ocean, anthropogenic disturbances coupled with climatic changes have been demonstrated to have a large impact on marine ecosystems, which may then cascade throughout the entire food web (Castini et al. 2008). This makes it essential to understand the mechanisms and pathways by which ecosystems respond. Climate change and overfishing are likely to cause rapid restructuring of highly productive marine ecosystems with effects on taxa throughout the pelagos and the benthos (Kirby et al. 2009). Unchecked, trophic cascades favouring lower trophic level groups may result in a proliferation of algal blooms (Castini et al. 2008) or jellyfish (Kirby et al. 2009). Such results suggest that efforts should be directed to preserve structure and functioning for the higher trophic levels (Castini et al. 2008).

In the short-term, we are unlikely to reverse current climate and human-induced effects via ecosystem resource management (Kirby et al. 2009). Instead, we must understand and adapt to new ecological regimes. This implies that ecosystem and fisheries management in the Antarctic must be fully integrated with an understanding of the ecological consequences of climate change. There will be a clear benefit from encouraging the development of science that predicts and assesses the uncertainty of effects and improves our predictive ability to estimate the timing and magnitude of resulting impacts.

\section{Re-examination of CCAMLR's precautionary approach}

The Convention for the Conservation of Antarctic Marine Living Resources (CCAMLR) is responsible for the management of sustainable and rational harvesting of all living resources in the Southern Ocean, with the exception of seals (Convention for the Conservation of Antarctic 
Seals) and whales (International Whaling Commission). CCAMLR manages within an ecosystem framework, taking into account ecosystem components other than targeted species. CCAMLR's responsibilities therefore extend beyond the management of harvesting, encompassing ecosystem and species conservation and related issues. CCAMLR is therefore at the forefront of the management debate when it comes to understanding how climate change affects species, and also, how its management practices may interact with these effects.

CCAMLR operates using the precautionary approach. Article II of the Convention states that, taking into account the state of available knowledge, harvesting should be conducted in such a manner that it prevents changes or minimizes the risk of changes to the marine ecosystem that are not potentially reversible over two or three decades.

CCAMLR has responded to this uncertainty (of different types - observation uncertainty, process uncertainty, implementation uncertainty) by operationalizing the precautionary approach - for instance through the use of a network of precautionary closed areas, precautionary target and limit reference points within decision rules and close monitoring for effects. However, the uncertainties considered thus far have largely been uncertainties associated with "status quo" environmental effects.

To move away from status quo considerations, recent ecosystem models used by CCAMLR's Working Group on Ecosystem Monitoring and Management have been constructed to take into account trends in the populations of Antarctic predators and prey, and to interpret change in relation to the changes that might be expected in the absence of fishing (SC-CCAMLR 2008/Annex 4, paragraph 2.65).

To fulfil its international obligation, CCAMLR will need to re-examine its approach to precaution in the light of the potential for major "natural" climate induced changes that we outline above. Where there is evidence of a regime shift in an ecosystem, or where there are apparent trends in a marine system such as may result from increasing temperatures, a number of ecosystem components may become vulnerable to (local) extinction. Under such scenarios, even moderate levels of harvesting may exacerbate any declines and populations may not be able to recover within two to three decades in the absence of fishing. Areas of particular concern may be the increased vulnerability of benthic Vulnerable Marine Ecosystems (VMEs) to damage when they are additionally stressed with increasing seawater temperatures and acidity, which is projected to be particularly severe for those at the limits of current aragonite/calcite solubility thresholds in Antarctic and deep waters (Royal Society 2005). Also of concern are the effects on bycatch species, particularly species dependent on fixed locations for their distribution or breeding, as they may be additionally stressed by changes to their environment.

CCAMLR may also need to consider whether and how ecosystems are likely to recover from perturbations in the face of climate change and how harvesting strategies may need to be modified to accommodate the objectives of Article II.

\section{Potential impacts associated with increased accessibility of the Antarctic}

Although all ecosystems can be expected to respond to climate change in the ways outlined above, high latitude ocean areas will experience a very fundamental change as they lose permanent sea ice cover. Currently high latitude embayed systems experience near year-round ice cover, which acts to dampen wind induced oceanographic features (surface drift, upwelling etc.), provides habitat and refuge for planktonic animals and habitat for higher predators. It can therefore be argued that these areas (Ross Sea, Weddell Sea, and smaller areas of ice retention around the continent) are likely to experience more significant ecosystem change than lower latitudes. Unfortunately, information about the marine foodweb in areas covered by seasonal sea ice is generally sparse, due in large part to the enormous logistic difficulties of undertaking science in these remote and challenging environments.

The threats to these areas come from their increasing accessibility - for example, from both legitimate and IUU fishing, from science and from tourism. There is therefore a continuing need for CCAMLR to engage to ensure that fishing in these previously ice-covered areas does not develop to the detriment of the marine ecosystem.

High latitude fisheries are currently either closed or managed under CCAMLR's new and exploratory fishery conservation measures. This precautionary approach has been adopted in order to ensure that adequate management information is available and so that risks to the ecosystem can be minimized. However, the only factors currently protecting toothfish populations in East Antarctica (FAO Statistical Areas 58.4.1 and 58.4.2) from increased IUU fishing are the low catch rates in these areas (and, hence, marginal economic benefits) and the relatively short access window (generally three to four months in the summer). Increased accessibility under conditions of reduced ice cover will inevitably increase risks from IUU fishing to these areas.

CCAMLR's application of the precautionary approach to fisheries development, exemplified in the CCAMLR new and exploratory fisheries conservation measures requires that fisheries should not expand faster than the acquisition of data required to manage them. Therefore, it might be expected that considering the poor state of our knowledge about currently ice-covered areas and the increased levels of uncertainty about ecosystem changes when ice cover reduces, that additional precaution should attend the development of exploratory fisheries in these areas. CCAMLR will therefore need to consider the extended 
use of Marine Protected Area (MPA) networks, additional requirements for data collection and research, additional restrictions on fishery development and activities (e.g. transhipment), and increased action against IUU vessels in previously ice-covered areas.

\section{Potential impacts on CCAMLR managed fisheries}

The impacts of climate change are likely to affect marine capture fisheries in a number of ways. Many impacts will be non-linear and some changes could be rapid and unpredictable. However, to safeguard against some of these potential changes, CCAMLR should examine various aspects of its stock assessment work, thereby making its work as robust as possible to future climate change scenarios.

There are three major fishing areas in the Antarctic: the South Atlantic basin, which holds the highest diversity of fisheries, comprising Antarctic krill (Euphausia superba), mackerel icefish (Champsocephalus gunnari Lönnberg) and Patagonian toothfish (Dissostichus eleginoides Smitt) around high latitude and sub-Antarctic island systems; the Southern Indian Ocean which has significant sub-Antarctic island fisheries for toothfish and icefish and small, perhaps marginal, continental fisheries; and the Ross Sea, which has a significant Antarctic toothfish fishery (Dissostichus mawsoni Norman). The potential for additional finfish fisheries is probably small, but the prospect for new large krill fisheries may be significant, particularly in the southern Indian Ocean sector.

Currently CCAMLR does not take into account environmental/recruitment relationships in any of its stock assessment models, although there is the potential to do so (Francis 2006, SC-CCAMLR 2007/Annex 4, para 2.51, SC-CCAMLR 2008/Annex 4, para 2.30). Furthermore, stock-recruit relationships are assumed to be known and stable. Should these change, for instance with a change in carrying capacity arising from climate change, it would be necessary to change the assumed stock-recruit relationship, which would require changing the stock reference points as well. Although the CCAMLR decision rule would probably be robust to this in the long-term, it is not clear how robust it would be in the short-term to rapid changes in recruitment dynamics; this requires additional investigation through modelling and management strategy evaluation.

A number of pieces of evidence suggest that recruitment in Patagonian toothfish, mackerel icefish and Antarctic krill, are all likely to be affected by changing ocean temperatures (Hill et al. 2005, Murphy et al. 2007, Belchier $\&$ Collins 2008). Analyses of recruitment indices show that recruitment is correlated with sea surface temperature with a lag time equal to the age of the cohort. In such analyses, sea surface temperatures may not necessarily be acting directly on recruitment (though they could be); rather, they should be considered as a convenient proxy for a range of other environmental variables. For all three species, different environmental variables could be acting on the populations. Though the precise nature of these interactions is as yet unclear, there is evidence for strong ecosystem concordance that allows ocean temperature to act as a proxy for other variables. Unfortunately much of this evidence is indirect and correlative, and since it is likely that if sea surface temperature is only a proxy for successful conditions (oceanographic flow and direction, productivity and ideal matching between prey and the occurrence of larval fish) it may not hold under future changed conditions.

Assessments of Antarctic krill currently rely upon a single synoptic survey undertaken in 2000 (Hewitt et al. 2004). Perversely, despite the fact that krill have been studied more extensively than icefish and toothfish since the 1960s, our knowledge of krill population dynamics, recruitment and ecosystem interactions remains relatively poor (Atkinson et al. 2004, 2008). Current surveys are not sufficient for understanding changing dynamics of recruitment in krill, and there is as yet no accepted method for using commercial data to understand real-time krill recruitment variability.

Long-term predictions of recruitment strength based on an understanding of oceanographic influences (Belchier \& Collins 2008) could be beneficial to stock assessments of toothfish. Relationships between stock recruitment and ocean temperatures may allow CCAMLR to manage krill fisheries in a more structured ecosystem framework (Murphy et al. 2007). Knowledge about recruitment and cohort strength would potentially allow CCAMLR to develop more realistic predictive models of stock abundance and cohort persistence, and to adjust harvesting regimes accordingly. However, these relationships may not be expected to hold under changing environmental conditions, because most such relationships are only valid for as long as the environmental regime remains relatively unchanged (Myers 1998). Consequently, and in the face of climate change, there is a pressing need for more regular monitoring of recruitment and population dynamics in all stocks. Potentially the most urgent need is to understand krill population dynamics in more detail and in real time as the fishery expands, and to develop a feedback management approach for this stock, particularly as the recruitment and availability of krill appears to influence the dynamics of other fishery systems. Management of all stocks would also benefit from a deeper understanding of the ecological and oceanographic causes of recruitment variability (Nicol 2006).

\section{Ecosystem monitoring}

CCAMLR developed the CCAMLR Ecosystem Monitoring Programme (CEMP) to indicate the short term response of key ecosystem components to localized environmental conditions. The primary objective of CEMP was to monitor air breathing predators in order to distinguish between the 
effects of natural variability and the potential impacts of commercial harvesting for krill. The harvesting of other species, or variability in other aspects of both krill-centric and non krill-centric ecosystems was not an objective of the programme, and CEMP is poorly equipped to detect changes in these components. Furthermore, under various climate change scenarios it is also likely that it will become increasingly difficult even to distinguish between natural and fishing-induced impacts on the narrow range of krillcentric predators considered by the programme. This is because the programme has not been designed optimally to detect these changes against a background of large, and unpredictable, natural fluctuations such as those likely to be seen during significant climate change. For example, even in the absence of any potential impacts from harvesting, it is likely that populations of dependent species will alter under a variety of climate change scenarios (SC-CCAMLR 2009/Annex 4, para 3.99-3.102, 7.11). This is already evident in the well-documented example of population movements of Adélie and chinstrap penguins in the Antarctic Peninsula region (Fraser et al. 1992, Trathan et al. 1996, Fraser \& Hofmann 2003, Forcada et al. 2006). Consequently, CCAMLR now needs to give consideration to how such factors might be distinguished in the future.

CEMP data do not directly indicate population size, which is the parameter that many conservation objectives attempt to control. Furthermore, CEMP data cannot be used in a standard environmental impact assessment framework as they lack control sites. Although CCAMLR has identified 17 Small Scale Management Units for the krill fishery in the south-west Atlantic, comprehensive suites of CEMP parameters are regularly collected for krill predators from only six of these, and by only three Members (Argentina, the UK and the USA). CCAMLR has also recently reported (SC-CCAMLR 2008) a gradual decline in the number of parameters regularly monitored and reported to the CCAMLR Secretariat, from a high point around 2000 back to levels last seen in the early 1990s. Four of the SSMUs have no coastal areas, thus they require quite a different monitoring approach to that adopted for coastal areas, but they may contain significant proportions of the krill population (Atkinson et al. 2008). Amongst the coastal monitoring sites, monitoring is almost exclusively undertaken during the summer breeding season, with little known about the behaviour and survivorship of animals in the winter. Finally, the placement of CEMP sites has been opportunistic (usually dependent upon existing national monitoring programmes) and is not appropriate for the broader scale monitoring required to detect impacts from fisheries and to separate these from those impacts that may arise from environmental forcing.

Identifying how CEMP data could be used in an ecosystem management strategy that goes beyond the narrow requirements of understanding the impacts of the krill fishery is an important challenge. Even a system that might be able to distinguish between fishery- and nonfishery relative effects on krill distribution is not yet proven (SC-CCAMLR 2003/Annex 4, para 2.7), and as we have earlier shown even this rather narrow task has been made much more difficult by the overlaying of the unpredictable effects of climate change onto an already highly variable ecosystem. Potential strategies for making the CEMP system more robust should, in our opinion, include consideration of the designation of true control SSMUs (i.e. those with no fishing, but with very similar ecosystem properties and predator population dynamics to other areas where fishing is allowed, and with the requirement that a comprehensive and coordinated suite of parameters are monitored in each area); the development of methods for inferring impacts between different CEMP sites and SSMUs; and the extension of the suite of monitored parameters to include other aspects of the ecosystem (especially the non-krill centric system) that are of interest in the context of climate change (see also Constable \& Doust 2009).

The expected ecosystem state is likely to shift as a consequence of climate change (and other influences on long-term dynamics). Comparisons with historical baselines are therefore likely to be misleading. It will therefore become increasingly difficult to determine whether CCAMLR is meeting its obligations under the Convention; and indeed, what those obligations mean, particularly Article II (3) (iii), the avoidance of impacts that are not potentially reversible in two or three decades. Thus, CCAMLR needs to revisit these objectives in terms of its management approaches, not only for harvested stocks, but also for other ecosystem components. For example, CCAMLR needs to evaluate ecosystem status in comparison with an assumed no-fishing state, rather than in comparison with a recent or past historical baseline (indeed, CCAMLR needs to recognize that actual or real historical baselines are no longer accessible, due to the major disturbance associated with two centuries of historical exploitation e.g. Bonner 1984, Kock 1992). This approach is similar to that taken by some Regional Fisheries Management Organisations already, such as the Western and Central Pacific Fisheries Commission which calculates current target (tuna) stock biomass with respect to the state that they would be without fishing, and does not compare these to historical baselines, which are not considered to be appropriate (Sibert et al. 2006). CCAMLR will then need to recognize the uncertainty inherent in such predictions of the no-fishing state and to devise approaches that can function effectively despite this uncertainty.

To improve our understanding of shifting baselines, CCAMLR must encourage a greater scientific research effort that encompasses the complete annual cycle allied with more frequent sampling. CCAMLR also needs to consider how best to utilize information from tourist/fishing vessels and the need to conduct designed research programmes that utilize such vessels (i.e. not just scientific 
observations). Such research should not be constrained (either spatially or temporally) to the operation of individual national programmes. Thus, CCAMLR needs to consider ship-based monitoring from tourist/fishing vessels on an annual scale comparable to that from CEMP predator monitoring.

\section{Concluding remarks}

We are moving towards a situation where we can begin to make reasonable, broad estimates of how variables such as temperature, precipitation and even ocean acidity and sea ice extent might change under a range of climate scenarios, and to consider possible impacts upon marine biota. Though such impacts need to be considered in the context of natural variability and in the context of other anthropogenic impacts, such as historical harvesting, signals from climate change are likely to become increasingly important within the Southern Ocean management framework.

CCAMLR is already at the forefront of the management debate when it comes to understanding how climate change affects species and also how its monitoring approach and management practices may interact with these effects. The background to these discussions is well documented in the CCAMLR Scientific Reports (available at www.ccamlr.org/ $\mathrm{pu} / \mathrm{e} / \mathrm{e}-\mathrm{pubs} / \mathrm{sr} / \mathrm{drt}$.htm). However, to maintain this impetus we suggest that in order for CCAMLR to fulfil its international obligations, it will be essential for it to determine the relative risks (uncertainties), impacts and timescales, of the various processes consequent on climate change.

With current levels of understanding, such a risk assessment should be feasible and should provide a focus for future work. As part of this process, we consider that it will be important to focus effort on those issues that have the biggest impact and where it is feasible to reduce uncertainty by the greatest amount. All of the risks described in this essay probably vary with latitude and longitude, with regional climate change, with local intensity of fishing, and with local foodweb structure, etc. Therefore, a plan for the future should involve shared responsibility (e.g. with SCAR) for each of the risks described.

\section{Acknowledgements}

This essay was developed from a review originally submitted to the CCAMLR Scientific Committee, Hobart, Australia, 27-31 October 2008 and revised for the CEP/CCAMLR Workshop, Baltimore, USA, 3-4 April 2009 and the meeting on the CCAMLR Working Group on Ecosystem Monitoring and Management, Bergen, Norway, 6-17 July, 2009. We are extremely grateful to the numerous colleagues, particularly from the CCAMLR community, who have given us the benefit of their constructive comments and criticisms, in particular Beth Fulton and Andrew Constable who reviewed an earlier version of this manuscript.

\section{References}

Agnew, D.J., Marlow, T.R., Lorenzen, K., Pompert, J., Wakeford, R.C. \& Tingley, G.A. 2003. Influence of Drake Passage oceanography on the parasitic infection of individual year-classes of southern blue whiting Micromesistius australis. Marine Ecology Progress Series, 254, 281-291.

Aoki, S., Bindoff, N.L. \& CHurch, J.A. 2005. Interdecadal water mass changes in the Southern Ocean between $30^{\circ} \mathrm{E}$ and $160^{\circ} \mathrm{E}$. Geophysical Research Letters, 32, 10.1029/2004GL022220.

Aronson, R.B., Thatje, S., Clarke, A., Peck, L.S., Blake, D.B., Wilga, C.D. \& Seibel, B.A. 2007. Climate change and invasibility of the Antarctic benthos. Annual Review of Ecology, Evolution, and Systematics, 38, 129-154.

Atkinson, A., Siegel, V., Pakhomov, E. \& Rothery, P. 2004. Long-term decline in krill stock and increase in salps within the Southern Ocean. Nature, 432, 100-103.

Atkinson, A., Siegel, V., Pakhomov, E.A., Rothery, P., Loeb, V., Ross, R.M., Quetin, L.B., Schmidt, K., Fretwell, P., Murphy, E.J., Tarling, G.A. \& Fleming, A.H. 2008. Oceanic circumpolar habitats of Antarctic krill. Marine Ecology Progress Series, 362, 1-23.

Baker, A.J., Pereira, S.L., Haddrath, O.P. \& Edge, K.A. 2006. Multiple gene evidence for expansion of extant penguins out of Antarctica due to global cooling. Philosophical Transactions of the Royal Society of London, B273, 11-17.

Barbraud, C. \& Weimerskirch, H. 2006a. Antarctic avian phenology and climate change. Journal of Ornithology, 147, 52-52.

Barbraud, C. \& Weimerskirch, H. 2006b. Antarctic birds breed later in response to climate change. Proceedings of the National Academy of Sciences, 103, 6248-6251.

Barnes, D.K.A., Hodgson, D.A., Convey, P., Allen, C.S. \& Clarke, A. 2006. Incursion and excursion of Antarctic biota: past, present and future. Global Ecology and Biogeography, 15, 121-142.

Beaugrand, G., Brander, K.M., Lindley, J.A., Souissi, S. \& Reid, P.C. 2003. Plankton effect on cod recruitment in the North Sea. Nature, 426, 661-664.

Belchier, M. \& Collins, M.A. 2008. Recruitment and body size in relation to temperature in juvenile Patagonian toothfish (Dissostichus eleginoides) at South Georgia. Marine Biology, 155, 493-503.

BRANDER, K.M. 2005. Cod recruitment is strongly affected by climate when stock biomass is low. ICES Journal of Marine Science, 62, 339-343.

Bonner, W.N. 1980. Whales. Poole: Blandford Press, 278 pp.

Bonner, W.N. 1984. Conservation in the Antarctic. In Laws, R.M., ed. Antarctic ecology, vol. II. London: Academic Press, 821-850.

Castini, M., Lovgren, J., Huelm, J., Cardinale, M., Molinero, J.C. \& Kornilovs, G. 2008. Multi-level trophic cascades in a heavily exploited open marine ecosystem. Philosophical Transactions of the Royal Society of London, B275, 1793-1801.

Chambers, L.E., Hughes, L. \& Weston, M.A. 2005. Climate change and its impact on Australia's avifauna. Emu, 105, 1-20.

Chan, J.C.L. \& LiU, K.S. 2004. Typhoon intensity in a warming world. Bulletin American Meteorological Society, 85, 660-661.

Cheung, W.W.L., Lam, V.W.Y., Sarmiento, J.L., Kearney, K., Watson, R. \& Pauly, D. 2009. Projecting global marine biodiversity impacts under climate change scenarios. Fish and Fisheries, 10, 235-251.

Chown, S.L. \& Convey, P. 2007. Spatial and temporal variability across life's hierarchies in the terrestrial Antarctic. Philosophical Transactions of the Royal Society of London, B362, 2307-2331.

Clarke, A. \& Harris, C.M. 2003. Polar marine ecosystems: major threats and future change. Environmental Conservation, 30, 1-25.

Collins, M.A., Ross, K.A., Belchier, M. \& Reid, K. 2007. Distribution and diet of juvenile patagonian toothfish on the South Georgia and Shag Rocks shelves (Southern Ocean). Marine Biology, 152, 135-147.

Constable, A.J. \& Doust, S. 2009. Southern Ocean sentinel - an international program to assess climate change impacts on marine ecosystems. Hobart, TAS: ACE CRC, Commonwealth of Australia, and WWF-Australia, 82 pp. 
Convey, P. 2006. Antarctic climate change and its influences on terrestrial ecosystems. In Bergstrom, D.M., Convey, P. \& Huiskes, A.H.L., eds. Trends in Antarctic terrestrial and limnetic ecosystems: Antarctica as a global indicator. Dordrecht: Springer, 253-272.

Convey, P. 2007. Influences on and origins of terrestrial biodiversity of the sub-Antarctic islands. Papers and Proceedings of the Royal Society of Tasmania, 141, 83-93.

Cook, A.J., Poncet, S., Cooper, A.P.R., Herbert, D.J. \& Christie, D. 2010. Glacier retreat on South Georgia and implications for the spread of rats. Antarctic Science, 22, 10.1017/S0954102010000064.

Croxall, J.P., Trathan, P.N. \& Murphy, E.J. 2002. Environmental change and Antarctic seabird populations. Science, 297, 1510-1514.

Forcada, J., Trathan, P.N. \& Murphy, E.J. 2008. Life history buffering in Antarctic mammals and birds against changing patterns of climate and environmental variation. Global Change Biology, 14, 2473-2488.

Forcada, J., Trathan, P.N., Reid, K. \& Murphy, E.J. 2005. The effects of global climate variability in pup production of Antarctic fur seals. Ecology, 86, 2408-2417.

Forcada, J., Trathan, P.N., Reid, K., Murphy, E.J. \& Croxall, J.P. 2006. Contrasting population changes in sympatric penguin species in association with climate warming. Global Change Biology, 12, 411-423.

FraNCIS, R.I.C.C. 2006. Measuring the strength of environment-recruitment relationships: the importance of including predictor screening within crossvalidations. ICES Journal of Marine Science, 63, 594-599.

Fraser, W.R. \& Hofmann, E.E. 2003. A predator's perspective on causal links between climate change, physical forcing and ecosystem response. Marine Ecology Progress Series, 265, 1-15.

Fraser, W.R., Trivelpiece, W.Z., Ainley, D.G. \& Trivelpiece, S. 1992. Increases in Antarctic penguin populations - reduced competition with whales or a loss of sea ice due to environmental warming. Polar Biology, 11, 525-531.

Frenot, Y., Chown, S.L., Whinam, J., Selkirk, P.M., Convey, P., Skotnicki, M. \& Bergstrom, D.M. 2005. Biological invasions in the Antarctic: extent, impacts and implications. Biological Reviews, 80, $45-72$.

Gille, S.T. 2002. Warming of the Southern Ocean since the 1950s. Science, 295, 1275-1277.

Gille, S.T. 2008. Decadal-scale temperature trends in the Southern Hemisphere Ocean. Journal of Climate, 21, 4749-4765.

Halpern, B.S., Walbridge, S., Selkoe, K.A., Kappel, C.V., Micheli, F., D'agrosa, C., Bruno, J.F., Casey, K.S., Ebert, C., Fox, H.E., Fujtta, R., Heinemann, D., Lenihan, H.S., Madin, E.M.P., Perry, M.T., Selig, E.R., Spalding, M., Steneck, R. \& Watson, R. 2008. A global map of human impact on marine ecosystems. Science, 319, 948-952.

Hewitt, R.P., Watkins, J.L., Naganobu, M., Sushin, V., Brierley, A.S., Demer, D., Kasatkina, S., Takao, Y., Goss, C., Malyshko, A., Brandon, M., Kawaguchi, S., Siegel, V., Trathan, P.N., Emery, J., Everson, I. \& Miller, D. 2004. Biomass of Antarctic krill in the Scotia Sea in January/February 2000 and its use in revising an estimate of precautionary yield. Deep-Sea Research II, 51, 1215-1236.

Hill, S.L., ReID, K. \& NoRTh, A.W. 2005. Recruitment of mackerel icefish (Champsocephalus gunnari) at South Georgia indicated by predator diets and its relationship with sea surface temperature. Canadian Journal of Fisheries and Aquatic Sciences, 62, 2530-2537.

Hogg, A.M., Meredith, M.P., Blundell, J.R. \& Wilson, C. 2008. Eddy heat flux in the Southern Ocean: response to variable wind forcing. Journal of Climate, 21, 608-620.

Hooper, M. 2007. The ferocious summer: Palmer's penguins and the warming of Antarctica. London: Profile Books, 320 pp.

Jenouvrier, S., Caswell, H., Barbraud, C., Holland, M., Stroeve, J. \& Weimerskirch, H. 2009. Demographic models and IPCC climate projections predict the decline of an emperor penguin population. Proceedings of the National Academy of Sciences, 27, 1844-1847.
Kirby, R.R., Beaugrand, G. \& Lindley, J.A. 2009. Synergistic effects of climate and fishing in a marine ecosystem. Ecosystems, 12, $548-561$.

Kоск, K.-H. 1992. Antarctic fish and fisheries. Cambridge: Cambridge University Press, $359 \mathrm{pp}$.

Laws, R.M. 1985. The ecology of the Southern Ocean. American Scientist, 73, 26-40.

Leaper, R., Cooke, J., Trathan, P.N., Reid, K., Rowntree, V. \& Payne, R. 2006. Global climate drives southern right whale (Eubalaena australis) population dynamics. Biology Letters, 2, 289-292.

Mayewski, P.A., Meredith, M.P., Summerhayes, C.P., Turner, J., Worby, A., Barrett, P.J., Casassa, G., Bertler, N.A.N., Bracegirdle, T., Garabato, A.C.N., Bromwich, D., Campbell, H., Hamilton, G.S., Lyons, W.B., MaAsch, K.A., Aoki, S., Xiao, C. \& van Ommen, T. 2009. State of the Antarctic and Southern Ocean climate system. Reviews of Geophyics, 47, RG1003.

Mollmann, C., Muller-Karulis, B., Kornilovs, G. \& St John, M.A. 2008. Effects of climate and overfishing on zooplankton dynamics and ecosystem structure: regime shifts, trophic cascade, and feedback loops in a simple ecosystem. ICES Journal of Marine Science, 65, 302-310.

Murphy, E.J., Trathan, P.N., Watkins, J.L., Reid, K., Meredith, M.P., Forcada, J., Thorpe, S.E., Johnston, N.M. \& Rothery, P. 2007. Climatically driven fluctuations in Southern Ocean ecosystems. Philosophical Transactions of the Royal Society of London, B274, 3057-3067.

Myers, R.A. 1998. When do environment-recruitment correlations work? Reviews in Fish Biology and Fisheries, 8, 283-305.

Nellemann, C., Hain, S. \& Alder, J., eds. 2008. In Dead Water - merging of climate change with pollution, over-harvest, and infestations in the world's fishing grounds. GRID-Arendal, Norway: United Nations Environment Programme, $64 \mathrm{pp}$.

NicoL, S. 2006. Krill, currents, and sea ice: Euphausia superba and its changing environment. BioScience, 56, 111-120.

Parkinson, C.L. 2002. Trends in the length of the Southern Ocean sea-ice season, 1979-99. Annals of Glaciology, 34, 435-440.

Parkinson, C.L. 2004. Southern Ocean sea ice and its wider linkages: insights revealed from models and observations. Antarctic Science, 16, 387-400.

Parmelee, D.F. \& Parmelee, J.M. 1987. Updated penguin distribution for Anvers Island, Antarctica. British Antarctic Survey Bulletin, No. 76, $65-73$.

Parry, L., Canziani, O.F., Palutikof, J.P., van Der Linden, P.J. \& Hanson, C.E., eds. 2007. Climate change 2007: impacts, adaptation and vulnerability. Contribution of Working Group II to the Fourth Assessment Report of the Intergovernmental Panel on Climate Change. Cambridge: Cambridge University Press, 976 pp.

Peck, L.S. 2005. Prospects for surviving climate change in Antarctic aquatic species. Frontiers in Zoology, 2, 10.1186/1742-9994-2-9.

PeCK, L.S. \& Conway, L.Z. 2000. The myth of metabolic cold adaptation: oxygen consumption in stenothermal Antarctic bivalves. Evolutionary Biology Bivalvia, 177, 441-450.

Peck, L.S., Convey, P. \& Barnes, D.K.A. 2006. Environmental constraints on life histories in Antarctic ecosystems: tempos, timings and predictability. Biological Reviews, 81, 75-109.

Peck, L.S., Webb, K.E. \& Bailey, D.M. 2004. Extreme sensitivity of biological function to temperature in Antarctic marine species. Functional Ecology, 18, 625-630.

Peck, L.S., Clark, M.S., Morley, S.A., Massey, A. \& Rossetti, H. 2009. Animal temperature limits and ecological relevance: effects of size, activity and rates of change. Functional Ecology, 23, 248-256.

Perry, A.L., Low, P.J., Ellis, J.R. \& Reynolds, J.D. 2005. Climate change and distribution shifts in marine fishes. Science, 308, 1912-1915.

Poncet, S. \& Poncet, J. 1987. Censuses of penguin populations of the Antarctic Peninsula, 1983-87. British Antarctic Survey Bulletin, No. 77, 109-129. 
Pörtner, H.O., Peck, L. \& Somero, G. 2007. Thermal limits and adaptation in marine Antarctic ectotherms: an integrative view. Philosophical Transactions of the Royal Society of London, B362, 2233-2258.

Quayle, W.C., Peck, L.S., Peat, H., Ellis-Evans, J.C. \& Harrigan, P.R. 2002. Extreme responses to climate change in Antarctic lakes. Science, 295, 645-645.

Rodionov, S.N. 2004. A sequential algorithm for testing climate regime shifts. Geophysical Research Letters, 31, 10.1029/2004GL019448.

Rootes, D.M. 1988. The status of birds at Signy Island, South Orkney Islands. British Antarctic Survey Bulletin, No. 80, 87-119.

Royal Society. 2005. Ocean acidification due to increasing atmospheric carbon dioxide. Policy document 12/05, June 2005. London: Royal Society, $60 \mathrm{pp}$.

SC-CCAMLR. 2003. Report of the Scientific Committee of the Commission for the Conservation of Antarctic Marine Living Resources, SC-CAMLRXXII/Annex 4. Hobart: CCAMLR.

SC-CCAMLR. 2007. Report of the Scientific Committee of the Commission for the Conservation of Antarctic Marine Living Resources, SC-CAMLRXXVI/Annex 4. Hobart: CCAMLR.

SC-CCAMLR. 2008. Report of the Scientific Committee of the Commission for the Conservation of Antarctic Marine Living Resources, SC-CAMLR-XXVII/Annex 4. Hobart: CCAMLR.

SC-CCAMLR. 2009. Report of the Scientific Committee of the Commission for the Conservation of Antarctic Marine Living Resources, SC-CAMLRXXVIII/Annex 4. Hobart: CCAMLR.

Sibert, J., Hampton, J., Kleiber, P. \& Maunder, M. 2006. Biomass, size, and trophic status of top predators in the Pacific Ocean. Science, 314, 1773-1776.

Shust, K.V. 1978. On the distribution and biology of members of the genus Micromesistius (Gadidae). Journal of Ichthyology, 18, 490-493.

Smale, D.A. \& Barnes, D.K.A. 2008. Likely responses of the Antarctic benthos to climate-related changes in physical disturbance during the 21 st century, based primarily on evidence from the West Antarctic Peninsula region. Ecography, 31, 289-305.

Solomon, S., Qin, D., Manning, M., Marquis, M., Averyt, K.B., Tignor, M., Miller, H.L. \& Chen, Z., eds. 2007. Climate change 2007: the physical science basis. Contribution of Working Group I to the Fourth Assessment Report of the Intergovernmental Panel on Climate Change. Cambridge: Cambridge University Press, 996 pp.

Stammerjohn, S.E., Martinson, D.G., Smith, R.C. \& Iannuzzi, R.A. 2008. Sea ice in the western Antarctic Peninsula region: spatio-temporal variability from ecological and climate change perspectives. Deep-Sea Research II, 55, 2041-2058.

Steig, E.J., Schneider, D.P., Rutherford, S.D., Mann, M.E., Comiso, J.C. \& Shindell, D.T. 2009. Warming of the Antarctic ice-sheet surface since the 1957 International Geophysical Year. Nature, 457, 459-U4.
Thompson, D.W.J. \& Solomon, S. 2002. Interpretation of recent Southern Hemisphere climate change. Science, 296, 895-899.

Trathan, P.N. \& MuRphy, E.J. 2002. Sea surface temperature anomalies near South Georgia: relationships with the Pacific El Niño regions. Journal of Geophysical Research, 108, 8075-8078.

Trathan, P.N., Croxall, J.P. \& Murphy, E.J. 1996. Dynamics of Antarctic penguin populations in relation to the inter-annual variability in sea-ice distribution. Polar Biology, 16, 321-330.

Trathan, P.N., Forcada, J. \& Murphy, E.J. 2007. Environmental forcing and Southern Ocean marine predator populations: effects of climate change and variability. Philosophical Transactions of the Royal Society of London, B362, 2351-2365.

Trathan, P.N., Murphy, E.J., Forcada, J., Croxall, J.P., Reid, K. \& Thorpe, S.E. 2006. Physical forcing in the southwest Atlantic: ecosystem control. In Boyd, I.L., Wanless, S. \& Camphuysen, C.J., eds. Top predators in marine ecosystems. Cambridge: Cambridge University Press, 28-45.

Trathan, P.N., Brierley, A.S., Brandon, M.A., Bone, D.G., Goss, C., Grant, S.A., Murphy, E.J. \& Watkins, J.L. 2003. Oceanographic variability and changes in Antarctic krill (Euphausia superba) abundance at South Georgia. Fisheries Oceanography, 12, 569-583.

Turner, J., Bindschadler, R., Convey, P., Di Prisco, G., Fahrbach, E., Gutt, J., Hodgson, D., Mayewski, P. \& Summerhayes, C., eds. 2009a. Antarctic change and the environment. Cambridge: Scientific Committee for Antarctic Research, 526 pp.

Turner, J., Comiso, J.C., Marshall, G.J., Lachlan-Cope, T.A., Bracegirdle, T., Maksym, T., Meredith, M.P., Wang, Z.M. \& Orr, A. 2009b. Non-annular atmospheric circulation change induced by stratospheric ozone depletion and its role in the recent increase of Antarctic sea ice extent. Geophysical Research Letters, 36, L08502.

Vaughan, D.G., Marshall, G.J., Connolley, W.M., King, J.C. \& Mulvaney, R. 2001. Climate change - devil in the detail. Science, 293, 1777-1779.

Vaughan, D.G., Marshall, G.J., Connolley, W.M., Parkinson, C., Mulvaney, R., Hodgson, D.A., King, J.C., Pudsey, C.J. \& Turner, J. 2003. Recent rapid regional climate warming on the Antarctic Peninsula. Climate Change, 60, 243-274.

Weimerskirch, H., Inchausti, P., Guinet, C. \& Barbraud, C. 2003. Trends in bird and seal populations as indicators of a system shift in the Southern Ocean. Antarctic Science, 15, 249-256.

Whitehouse, M.J., Meredith, M.P., Rothery, P., Atkinson, A., Ward, P. \& KoRB, R.E. 2008. Rapid warming of the ocean around South Georgia, Southern Ocean, during the 20th century: forcings, characteristics and implications for lower trophic levels. Deep-Sea Research I, 55, 1218-1228.

Williams, T.D. 1995. The penguins. New York: Oxford University Press, 295 pp. 